\title{
Research Progress of Fluorescent Molecular Probe for Cyanide Ion
}

\author{
L.M. Zhou, J. Li, N. Wang, C.H. Lu \& B. Liu \\ Department of CWC Implementation, Institute of Chemical Defence, Beijing, China, 102205
}

\begin{abstract}
Cyanide ion, a kind of extremely toxic chemical, is used as chemical warfare agents, as well as civilian chemical raw stuffs. Many detection methods for cyanides ion have been researched. This paper reviewed on some research progress of fluorescent molecular probe for cyanide ion in recent 5 years in worldwide, as a conclusion, the authors assessed the applicability of fluorescent probes with different identifying mechanisms for cyanides in water.
\end{abstract}

KEYWORD: Fluorescent molecular probe; cyanide ion; research progress

\section{INTRODUCTION}

Cyanides are extremely toxic substances, with micro lethal dosage. Except for taking accidentally, the vapor and dust of cyanides can access bodies by respiratory and digestive tract. Cyanides even combine with ferric ion of cytochrome oxidase in vivo by permeating through skins, which lead to the cells losing the ability of adsorbing and delivering oxygen, accordingly oxygen lacked in bodies, eventually causes mammals poisoning and death[1]. However, cyanides are omnipresent in human's daily life, for example, in gold mining, electroplating and metallurgy industry, moreover, cyanides utilized as raw materials of synthetic resin, medicines, pesticides[2]. Cyanides are also the precursors of chemical warfare agent, and they were ever utilized as chemical warfare agent during WWI, at the end of WWII, Japan abandoned a large number of chemical weapons contained cyanides in China[3], which have given rise to severe pollution of soil and water source in many areas. Thus development of trace amount detection method is vital in environment monitoring and medical research.

So far, there have been many reported detection and analysis methods for cyanide ion $\left(\mathrm{CN}^{-}\right)$in literatures, including titrimetric analysis[4], electrochemical process [5], ion chromatography[6], and biosensor[7]. Nevertheless, those methods utilized to identify $\mathrm{CN}^{-}$are not only timeconsuming and operational complex, but also needing high precision instruments. While fluorescent molecular probe method has some advantages of simple operation, good selectivity, high sensitivity, as well as realizing on-line analysis, immediate analysis and cells imagining even without expensive instruments. In 2009, Huang Zhiping[8] reviews on fluorescent detection of $\mathrm{CN}^{-}$, Mu Xin[9] reviews on the application of triargylhydroboron detection for fluorinion and $\mathrm{CN}^{-}$. This paper focuses on some worldwide research progress of fluorescent molecular probe for $\mathrm{CN}^{-}$in recent 5 years, furthermore, assesses the applicability of different mechanisms of fluorescent molecular probe for $\mathrm{CN}^{-}$in water.

\section{RESEARCH PROGRESS OF DETECTION FOR CYANIDE ION}

According to identification mechanisms, the acceptor molecules of fluorescent molecular probe for cyanide ion can be classified into 3 types, i.e. acceptor molecules[10] of $\mathrm{CN}^{-}$being bonded by $\mathrm{H}-$ bond or electrostatic interaction; acceptor molecules[11,12] contain metal ion or lewisite acid; reaction type acceptor molecules (so called chemometry recogizer)[13,14]. They are accounted for as follows.

\subsection{Fluorescent molecular probe based on H-bond interaction}

H-bond interaction is a common used method to identify anion. Compared to other anion, cyanide ion is not a stronger acceptor of $\mathrm{H}$-bond, but it is reported that $\mathrm{CN}^{-}$can be identified by $\mathrm{H}$-bond. Odago[15] illustrats colorimetric $\mathrm{CN}^{-}$probe $\mathrm{P} 1$ 
which contains 2 thiocarbamide groups (scheme 1). In DMSO, P1 is pale yellow solution, after $\mathrm{CN}^{-}$is added, the solution color turns into red, thus $\mathrm{CN}^{-}$is identified by visual sensing detection. Then polar solvent methanol is added into the solution, solution color recovers from red to yellow. By ${ }^{1} \mathrm{H}$ NMR, it is verified that the de-proton process of thiocarbamide group is indeed occurred. The mechanism can be explained as: after $\mathrm{CN}^{-}$is added, the de-proton process of thiocarbamide accelerate the intramolecular charges transferring (ICT). Sukdeb[16] reports probe $\mathrm{P} 2$ that contains imidazole group. In HEPES: $\mathrm{CH}_{3} \mathrm{CN}=1: 1$ solution, both $\mathrm{P} 2 \mathrm{a}$ and $\mathrm{P} 2 \mathrm{~b}$ can identify $\mathrm{CN}^{-}$, the color of $\mathrm{P} 2 \mathrm{a}$ turns from pale yellow to red, while P2b turns from red to dark blue. Moreover, P2a also can identify $\mathrm{CN}^{-}$by fluorescent ratio. The minimum detection limit of $\mathrm{P} 2 \mathrm{a}$ is $0.06 \mathrm{mg} / \mathrm{L}$, while $\mathrm{P} 2 \mathrm{~b}$ is $0.078 \mathrm{mg} / \mathrm{L}$, which are approximate to the WHO's drinking water standard what of $0.05 \mathrm{mg} / \mathrm{L}[17]$.

\subsection{Fluorescent molecular probe based on metal coordination compounds}

On account of strong affinity of $\mathrm{CN}^{-}$with cupric ion or gold ion, they can form stable coordination compounds $[\mathrm{Cu}(\mathrm{CN}) \mathrm{X}]^{\mathrm{n}-}$ and $[\mathrm{Au}(\mathrm{CN}) \mathrm{X}]^{\mathrm{n}-}$, utilizing the mechanisms to design fluorescent molecular probes are being paid close attention to. The most important advantage of this kind of probe is to realize detection of $\mathrm{CN}^{-}$in water. Zhai Qiuge[18] selects the coordination compound of $\mathrm{Pd}^{2+}$ combined with molecular wire polymeride PDPC which contains pyridine functional group as research system.
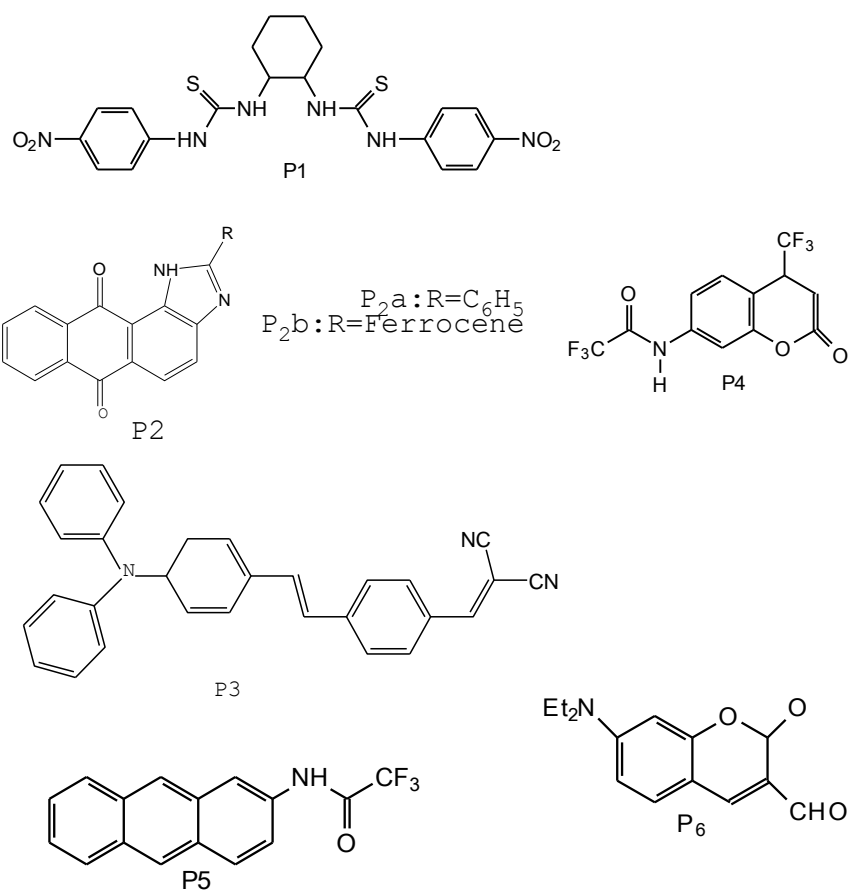
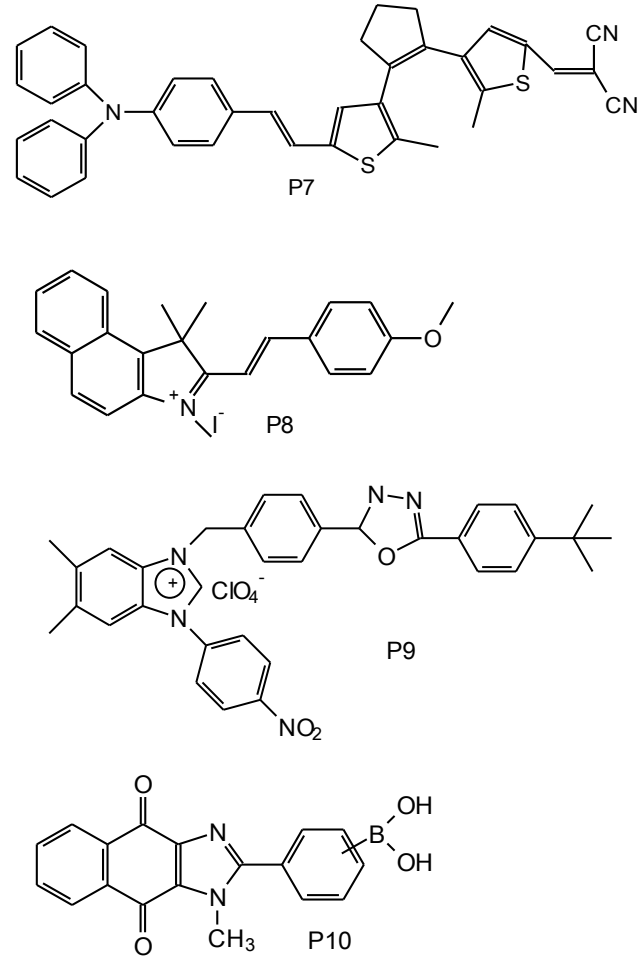

Scheme 1 Structures of related fluorescent molecular probes

As $\mathrm{CN}^{-}$has stronger combination ability with $\mathrm{Pd}^{2+}$, PDPC can be released from coordination compounds and recovers the fluorescence of PDPC. According to the variation of fluorescence intensity, the selective detection of $\mathrm{CN}^{-}$can be done, the lower detection limit is $0.0026 \mathrm{mg} / \mathrm{L}$. Huang Xianhong[19] develops a new method to detect $\mathrm{CN}^{-}$ in water, which utilizes the difference of combination ability of $\mathrm{CN}^{-}$and cupric ion combined with oligonucleotides chain(FAM-DNA) marked with fluorescein. An oligonucleotides chain marked with fluorescein is selected, then it coordinates with cupric ion to form a stable coordination compound (FAM-DNA- $\mathrm{Cu}^{2+}$ ), thus the fluorescence of the system is canceled. Due to owning stronger combination ability with $\mathrm{Cu}^{2+}$, when $\mathrm{CN}^{-}$is added into the system, it coordinates with $\mathrm{Cu}^{2+}$, which renders FAM-DNA be released from coordination system, and recovers the fluorescence of system. The detection limit of $\mathrm{CN}^{-}$ in water is $0.00052 \mathrm{mg} / \mathrm{L}$, possessing higher selectivity and potential value of application. Li Chao[20] improves the solubility of betacyclodextrin in water by covering squaric acids(SQ) with beta-cyclodextrin. In the covered compound, the 2 benzene rings of clathrate compound are implanted into 2 different vacant intracavities, while middle four-membered ring is naked outside. Squaric acids(SQ) is a ideal probe for $\mathrm{CN}^{-}$because of its intensive and narrow absorbency in near infrared region, as well as its specific sensitivity to cyanides. The coverage of $\beta$ - beta-cyclodextrin renders insoluble SQ can selectively identify $\mathrm{CN}^{-}$ in pure water system without chemical modification. 
After $\mathrm{CN}^{-}$is added, SQ $634 \mathrm{~nm}$ is color fading, the logarithm of absorbance of SQ presented good linear relation with concentration of $\mathrm{CN}^{-}$(the concentration of $\mathrm{CN}^{-}$from $0.26 \mathrm{mg} / \mathrm{L}$ to $8.32 \mathrm{mg} / \mathrm{L}$ ).

\subsection{Fluorescent molecular probe based on reactions type}

With weak alkalinity and strong nucleophilicity, $\mathrm{CN}^{-}$is utilized to design chemical reaction type fluorescence molecular probe, which has been a hot research subject. In recent years there have been many related reports, that in accordance with the additive subjects, the probes can be classified into addition reaction of $\mathrm{C}=\mathrm{C}$ bond, $\mathrm{C}=\mathrm{O}$ bond, $\mathrm{C}=\mathrm{N}$ bond, as well as lacking of electric center of boron. Lin[21] develops a kind of new $\mathrm{CN}^{-}$colorimetric and 'turn on' fluorescent probe $\mathrm{P} 3$, which is free of disturbance by other anions in THF aqueous solution. The identifying mechanism of $\mathrm{CN}^{-}$could be explained as: cyanoethylene unit in $\beta$ site of reagent reacted with $\mathrm{CN}^{-}$and the additive product of nucleophilic addition owned $\pi$ bond which are conjugate bond. The minimum detection limit of $\mathrm{CN}^{-}$is $0.17 \mathrm{mg} / \mathrm{L}$, and the method being of low sensitivity, only can be used to monitor sewage discharge. $\mathrm{Li}[22]$ developes a fluorescent molecular probe $\mathrm{P} 4$, which is based on a colorimetric reaction of 7-trifluoroacetamidocumarin and $\mathrm{CN}^{-}$. With simple structure and fast response, $\mathrm{P} 4$ can detect $\mathrm{CN}^{-}$in aqueous solution companied by a few disturbances from other coexisted anion. The ion identifying mechanism is: $\mathrm{CN}^{-}$reacts with the probe to form 1:1 chemometry formula by nucleophilic impacting of carbonyl group of the probe, the process has been proved by the research of working curve, ${ }^{1} \mathrm{H}-\mathrm{NMR}$ and mass spectrum. The enhanced fluorescence intensity of the probe, supported by DFT/TDDFT calculating, is mainly caused by the improvement of ITC. The detection limit is $0.0078 \mathrm{mg} / \mathrm{L}$, response time is less than 30 sec., thus, the probe can be used to detect $\mathrm{CN}^{-}$in water. $\mathrm{Yu}$ [23] designs and synthesizes a new ratio fluorescent probe P5, N-2anthracyltrifluoroacetamide. The anthracyl fragment of P5 works as fluorophore, while trifluoreacetamide works as the acceptor for $\mathrm{CN}^{-}$. Compared to other reported $\mathrm{CN}^{-}$probe of trifluoreacetamide derivatives, P5 presents higher sensitivity, and the differences are obvious, $\mathrm{CN}^{-}$can be identified even if the concentration is as low as $0.1 \mathrm{mg} / \mathrm{L}$. Kim[24] utilizes a simple chemometry sensor P6, which uses aldehyded coumarin as Micheal acceptor with double activity to identify $\mathrm{CN}^{-}$in water. The Micheal additive reaction of $\mathrm{P} 6$ and $\mathrm{CN}^{-}$has presented good selectivity and higher sensitivity. With the $\mathrm{CN}^{-}$added, the color of the probe changes with the variation of fluorescence, mmol level $\mathrm{CN}^{-}$ can be identified by the naked eyes. Jin Jiayu[25] synthesizes bi(vinylthiophene) probe P7. In the motivation of UV light, P7 does not emit fluorescence, which means the adding of dicyanoethylene completely cancells the fluorescence of triphenylamine, which may be caused by the inactivation of photoinduction electron transfer (PET). When $\mathrm{CN}^{-}$is added, $\mathrm{CN}^{-}$impacts dicyanoethylene, nucleophilic addition is occured and anions are produced, PET is terminated and the fluorescence of donor can be recovered and enhanced. Thus the fluorescence emission spectrum is same as triphenylamine. The detection limit of $\mathrm{CN}^{-}$is $0.45 \mu \mathrm{g} / \mathrm{L}$. Sun[26] developes a high selectivity of 'turn-on' type fluorescent probe P8, P8 is based on $\mathrm{CN}^{-}$being loaded on benzoindoles as fluorescent group and bonding site. $\mathrm{CN}^{-}$is identified by the nucleophilic reaction of $\mathrm{CN}^{-}$and benzoindoles kation group, the process is companied with the obviously fluorescence enhanced and color changed. P8 has higher selectivity for $\mathrm{CN}^{-}$in water, $\mathrm{pH}$ range 6-9, detection limit is $0.0012 \mathrm{mg} / \mathrm{L}$. The probe can be used to identify $\mathrm{CN}^{-}$in drinking water, and a set of detection paper is developed.

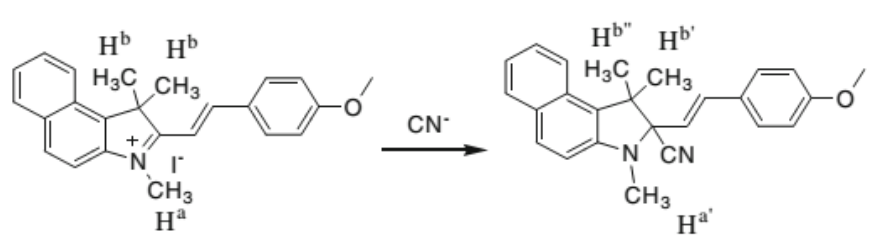

Scheme 2 the mechanism of $\mathrm{P} 8$ probe identify $\mathrm{CN}^{-}$

Mashraqui[27] designs and synthesizes a new $\mathrm{CN}^{-}$chemometry probe $\mathrm{P} 9$, in DMSO, $\mathrm{P} 9$ presents selective colorimetric and 'turn-on' fluorescent response to $\mathrm{CN}^{-}$. When $\mathrm{CN}^{-}$exists, the red shift is observed in $108 \mathrm{~nm}$, as well as 5 times enhancing in fluorescence, which is proved by ${ }^{1} \mathrm{H}-\mathrm{NMR}$. That is an addition reaction process, not only the photoelectron and energy transformation is same, but also the ICT fluorescence enhancing of P9-CN additive product is same. Common anions such as $\mathrm{F}^{-}$, $\mathrm{Cl}^{-}, \mathrm{AcO}^{-}, \mathrm{SCN}^{-}, \mathrm{HSO}_{4}^{-}, \mathrm{NO}_{3}^{-}, \mathrm{Br}^{-}, \mathrm{I}^{-}$and $\mathrm{H}_{2} \mathrm{PO}_{4}^{-}$ have no influence or no obvious disturbance in $\mathrm{CN}^{-}$ identifying.

Jamkratoke[28] evelopes a kind of new fluorescent qualitative and quantitative method which utilizes naphthoquinone imidazolyboronic acid fluorescent probe P10(m-NQB and p-NQB), together with cationic surface active agent (cetyltrimethyl ammonium bromide) to identify $\mathrm{CN}^{-}$in water, and the mechanism shows as scheme. Due to the micro emulsion of CTAB, the boric part of P10 probe gives micro-mol level quantitative detection limit for $\mathrm{CN}^{-}$, thus the micro emulsion system presents very high selectivity for detection of $\mathrm{CN}^{-}$. In best conditions, in 460nm, linearity range of fluorescent intensity of $\mathrm{m}-\mathrm{NQB}$ and $\mathrm{p}-\mathrm{NQB}$ is 
$0.013 \mathrm{mg} / \mathrm{L} \sim 39 \mathrm{mg} / \mathrm{L}$, detection limit is $0.013 \mathrm{mg} / \mathrm{L}$, P10 can be used to identify $\mathrm{CN}^{-}$in water.

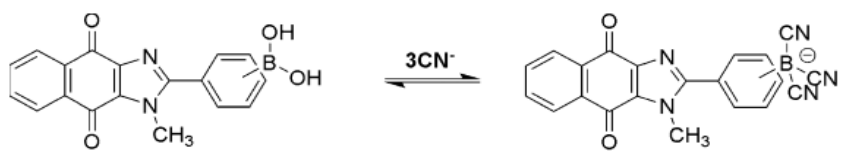

Scheme 3 the mechanism of $\mathrm{P} 10$ probe identify $\mathrm{CN}^{-}$

\subsection{The analysis of applicability for fluorescent molecular probe used in environment monitoring}

Cyanides belong to second species pollutants in Chinese national integrated wastewater discharge standard, the highest discharge concentration is $0.5 \mathrm{mg} / \mathrm{L}[29]$; the level 3 standard of $\mathrm{CN}^{-}$in surface water is $0.2 \mathrm{mg} / \mathrm{L}[30]$; the level 3 standard of $\mathrm{CN}^{-}$ in underground water is $0.05 \mathrm{mg} / \mathrm{L}[31]$; the standard limiting value of $\mathrm{CN}^{-}$in destruction of Japanese abandoned chemical weapons is $0.01 \mathrm{mg} / \mathrm{L}[32]$; the limiting value of $\mathrm{CN}^{-}$in drinking water is $0.05 \mathrm{mg} / \mathrm{L}$ [33], which is same with drinking water standard recommended by WHO. In China, the recommended detection methods for $\mathrm{CN}^{-}$are 'isonicotinic acid-pyrazolone method' and 'pyridinebarbituric colorimetric method', the detection limit are respectively $0.004 \mathrm{mg} / \mathrm{L}$ and $0.002 \mathrm{mg} / \mathrm{L}$. Based on the above analysis, only the fluorescent molecular probe being based on reaction type, giving response in aqueous solution can be used to identify the $\mathrm{CN}^{-}$ contained in above-mentioned water types.

\section{OUTLOOK}

Though the researches of fluorescent molecular probes for cyanide ion are very hot subjects, more of them focus on theoretic research, lacking of practical application. H-bond interaction type probes are weak in sensitivity; coordination type probes have good solubility in water but the sensitivity cannot meet the needs of water quality detection; reaction type probes have no problem in selectivity and sensitivity, but the solubility is poor in aqueous solution, and more of them have to be conducted in organic solution, sometime the reaction are relative slow. Thus developing some fluorescent molecular probes[34] for cyanide ion with characteristics of good selectivity, high sensitivity, good solubility, fast response and practical application are the goals of future research.

\section{REFERENCES}

[1] Army, Marine Corps, Navy, Air Force, Potential Military Chemical/Biological Agents and Compounds.
Multiservice tactics, techniques, and procedures, USA, 2005.

[2] C. Young, L. Tidwell, C. Anderson, Cyanide: Social, Industrial, and Economic Aspects, Minerals, Metals, and Materials Society, Warrendale, 2001.

[3] S.Hanaoka,K. Nomura,S.Kudo, Identification and quantitative determination of diphenylarsenic compounds in abandoned toxic smoke canisters. J.Chromatogr. A, 2005, 1085:213-223.

[4] T.Suzuki, A.Hioki, M.Kurahashi, Development of a Method for Estimating an Accurate Equivalence Point in Nickel Titration of Cyanide Ions. Anal. Chim. Acta., 2003,476:159-165.

[5] Vallejo-Pecharromán B, Luque de Castro MD,Determination of cyanide by a pervaporation-UV photodissociation-potentiometric detection approach[J]. Analyst, 2002, 127:267-270.

[6] T.T. Christisona, J.S. Rohrera. Direct Determination of Free Cyanide in Drinking Water by Ion Chromatography with Pulsed Amperometric Detection. J.Chromatogr. A, 2007, 1155 (1): 31-39.

[7] D.Shan,C.Mousty,S.Cosnier, Subnanomolar Cyanide Detection at Polyphenol Oxidase/Clay Biosensors.Anal. Chem., 2004, 76:178-183.

[8] Huang zhiping, Li shuhai, Li huizhuo, Zeng kai, Research Progress of Fluorescent Detection Method for Cyanide Ion. Guangdong Chemical Engineering., 2009, 36(6):249251.

[9] Mu xin, Liu shujuan, Dai chunlei, Ma tingchun, Zhao qiang, Ling qidan, Huangwei,. Research and Application of Triaryl borane in Organic Electronics., Science of China: Chemistry., 2010,40(8):979-990.

[10] H.Miyaji, J.L.Sessler, On-the-shelf colorimetric anion sensors. Angrew Chem Int Ed, 2001, 40:154-157.

[11] C-F.Chow, M.H.W.Lam, W-Y.Wong, A heterobimetallic ruthenium(II)-copper(II) Donor-acceptor complex as a chemodosimetric ensemble for selective cyanide detection. Inorg Chem, 2004, 43:8387-8393.

[12] S-Y.Chung, S-W.Nam, J.Lim, S.Park, J.Yoon, A highly selective cyanide sensing in water via fluorescence change and its application to in vivo imaging. Chem Commun, 2009, 2866-2868.

[13] Z.Ekmekci, M.D.Yilmaz, E.U.Akkaya, A monostyrylboradiazaindacene (BODIPY) derivative as colorimetric and fluorescence probe for cyanide ions. Org Lett., 2008, 10:461-464.

[14] Y.Sun, G.Wang, W.Guo, Colorimetric detection of cyanide with $\mathrm{N}$-nitrophenyl benzamide derivatives. Tetrahedron, 2009, 65:3480-3485.

[15] M.O.Odago, D.M.Colabello, A.J. Lees, A Simple Thiourea Based Colorimetric Sensor for Cyanide Anion. Tetrahedron, 2010, 66: 7465-7471.

[16] Sukdeb Saha, Amrita Ghosh, Prasenjit Mahato, Sandhya Mishra, Sanjiv K. Mishra,E. Suresh, Satyabrata Das and Amitava Das, Specific Recognition and Sensing of CN- in Sodium Cyanide Solution. Org. Lett.. 2010,12:3406-3409.

[17] World Health Organization: Guidelines for DrinkingWater Quality; Third Ed., Vol.1, Geneva: 2004.

[18] Zhai qiuge, Huang hongmei, Wang kemin, Tan weihong, Huang shansheng, Jin yan, Li bangyue, Research of Molecule Wireless Coordination Compounds for Cyanide Anions, Chemical Journal of Chinese University, 2005,26(1):46-48.

[19] Huang xianhong, Zhang guanxin, Zhang deqing, Enhanced Fluorescence Type Cyanide Ion Sensor Based on Coordination Compound DNA-Cu(II) Marked with Fluorescein. Journal of Chemical, 2012, 70:2133-2136.

[20] Li chao, Wang weibo, Wang xuesong, Zhang baowen, Cao yi,. Cyclodextrin SQ Covered with $\beta$ - beta- 
cyclodextrin Identify Cyanide Ion in Water. Photographic science and photochemistry., 2005,23(6):401-406.

[21] Y.-D.Lin, Y.-S.Peng,W. Su,C.-H.Tu,C.-H. Sun,T.J. Chow, A highly selective colorimetric and turn-on fluorescent probe for cyanide anion. Tetrahedron, 2012, 68:2523-2526.

[22] H.Li, B.Li,L.-Y. Jin,Y.Kan,B.Yin, A rapid responsive and highly selective probe for cyanide in the aqueous environment. Tetrahedron, 2011, 67:7348-7353.

[23] H.Yu, Q.Zhao, Z.Jiang, J.Qin, Z.Li, A ratiometric fluorescent probe for cyanide: Convenient synthesis and the proposed mechanism. Sensors \& Actuators B, 2010, 148:110-116.

[24] G.-J.Kim,H.-J. Kim. Coumarinyl aldehyde as a Michael acceptor type of colorimetric and fluorescent probe for cyanide in water. Tetrahedron Lett., 2010,51:2914-2916.

[25] Jin jiayu, Photochromic Material of Dithiophene Ethylene with Ion Identification and Dye Sensitized Function., East China University of Science and Technology, Doctoral Dissertation, Shanghai, 2013.

[26] Y.Sun,S.Fan,D.Zhao,L.Duan,R.Li, A Fluorescent TurnOn Probe Based on Benzo [e] Indolium for Cyanide Ion in Water With High Selectivity. J Fluoresc, 2013, 23:12551261.
[27] S.H.Mashraqui,R.Betkar,S.Ghorpade,A.Frontera,A new benzimidazolium incorporated chemodosimeter affording dual chromogenic and fluorescence switch-on signaling for the selective targeting of cyanide. J Incl Phenom Macrocycl Chem, 2013, 76:293-300.

[28] M.Jamkratoke,G.Tumcharern,T.Tuntulani,B,Tomapatanag et, A Selective Spectrofluorometric Determination of Micromolar Level of Cyanide in Water Using Naphthoquinone Imidazole Boronic-Based Sensors and a Surfactant Cationic CTAB Micellar System. J Fluoresc, 2011, 21:1179-1187.

[29] Integrated Wastewater Discharge Standard, (GB89781996), Beijing: 1996.

[30] Surface Water Quality Standard, (GB3838-2002), Beijing: 2002.

[31] Underground Water Quality Standard, (GB/T148481993), Beijing: 1993.

[32] Destruction of Japanese Abandoned Chemical Weapons Contaminants Concentration in Surface Water Standard in China, (B19613-2003), Beijing: 2003.

[33] Standard for Drinking Water Quality, (B5749-2006), Beijing: 2006.

[34] Water quality of cyanide determination method, (B74871987), Beijing: 987. 